\title{
Connatal Pelizaeus-Merzbacher disease: A missense mutation in exon 4 of the proteolipid protein (PLP) gene
}

\begin{abstract}
We investigated the proteolipid protein (PLP) gene in two brothers in a Japanese family with a connatal form of Pelizaeus-Merzbacher disease (PMD). Direct sequencing of the PLP gene revealed an A-to-T transition in exon 4, which led to an Asp-to-Val substitution at residue 202. Their mother was confirmed to be heterozygous for the mutation. The mutation was not found in $78 \mathrm{X}$ chromosomes of normal Japanese individuals. A correlation between the clinical severity of the disease in the brothers and the Asp202-to-Val mutation in the PLP gene was suggested.
\end{abstract}

Key words Dysmyelination · Laryngo-tracheomalacia Missense mutation · Pelizaeus-Merzbacher disease Proteolipid protein (PLP)

\section{Introduction}

Pelizaeus-Merzbacher disease (PMD) is a rare, sex-linked, recessive dysmyelinating disease of the central nervous system associated with defects in the proteolipid protein (PLP) gene (Gencic et al. 1989). It has been demonstrated that PLP, the most abundant myelin protein in the brain, is markedly decreased in PMD patients (Koeppen et al. 1987). Clinically, two types of PMD have been recognized. (1) The classic type, with onset in infancy and death in late adolescence or young adulthood, is characterized by initial signs of nystagmus and involuntary head movements. (2) The connatal type shows rapid progression with various neurological symptoms and is fatal in infancy or childhood.

\section{Nagao $(\bowtie) \cdot$ J. Kadowaki}

Department of Pediatrics, National Otaru Hospital, Department of Pediatrics, 3-24-1 Nagahashi, Otaru, Hokkaido 047-0036, Japan Tel. +81-134-32-5131; Fax +81-134-29-2164 e-mail: CXQ04341@niftyserve.or.jp

M. Nagao $\cdot$ J. Kadowaki

Department of Pediatrics, Sapporo Medical University, Sapporo, Japan
The PLP gene is assigned to human Xq22 (Mattei et al. 1986). Molecular analyses of the PLP gene have revealed various mutations; deletion or duplication of the gene, missense mutations in various exons, and a mutation in the $5^{\prime}$ untranslated region. Thus far, only $10 \%-30 \%$ of patients with this disorder have been shown to have exonic mutations in the PLP gene. However, patients with exonic mutations tend to have more severe clinical manifestations than those not carrying the mutations (Inoue et al. 1997). We report a novel missense mutation in exon 4 of the PLP gene, which led to a severe phenotype of PMD, in two siblings in a Japanese family.

\section{Subjects and methods}

The patients were two brothers ( 8 and 12 years old) with severe developmental delay, spastic extremities, and respiratory difficulties. Laryngeal stridor and dyspnea appeared within a few days after birth and intensive respiratory care was necessary for both children. The presence of laryngotracheomalacia was suggested by microscopy. Nystagmus was also noted at that time. The clinical course, neuroradiological features, and abnormalities of the auditory brain-stem responses (ABR) were consistent with a connatal form of PMD. Their parents are healthy and unrelated. No family members were known to have a progressive neurological disease.

Genomic DNA samples were prepared from peripheral blood leukocytes. The coding sequence and flanking region of each exon of the PLP gene were scanned for mutations by polymerase chain reaction (PCR) single-strand conformation polymorphism (SSCP) analysis. The nucleotide sequence of each set of primers has been described previously (Doll et al. 1992). The exonic regions containing a variant sequence were subjected to direct sequencing analysis, using $\left[{ }^{35} \mathrm{~S}\right]$-dATP (Amersham Radiochemicals, Amersham, UK) and a cycle sequencing kit (Perkin-Elmer Cetus, Norfolk, CT, USA). The patients and their parents were characterized with respect to the mutation genotype in the 
PLP gene. Sau 3A1 digestion of the PCR product, which was amplified by using mismatched primers (4A-Sau3A1; 5'-TTTGTGGGCATCACCTATCCC-3', 4B-Sau3A1; 5' AACTCACCATACATTCTGGCA-3'), was performed to detect the presence of the Asp202-to-Val mutation in the variant allele. The presence of the mutation was also investigated in 50 unrelated healthy Japanese controls (22 males and 28 females).

\section{Results and discussion}

A combination of SSCP and direct sequencing of PCR amplified DNA revealed an A-to-T transition in exon 4 of the PLP gene, which led to an Asp202-to-Val substitution (Fig. 1 ). This mutation was observed in both of the affected male siblings. Their mother was shown to be heterozygous for the mutation by the same method. The father had a normal sequence. The previously reported polymorphism, a T-to-C change in the third position of codon 202 (Trofatter et al. 1991), was not observed in the family members or in the healthy Japanese individuals examined. We then devised a rapid and general technique to identify this mutation (Fig. 2). А Sau 3A1 restriction site was artificially created by sitedirected mutagenesis in the amplification step. The normal DNA fragment amplified using mismatched primers (4ASau3A1 and 4B-Sau3A1) has a Sau 3A1 site which digests the 186-bp fragment into 153- and 33-bp fragments. The PCR product of the variant allele was not digested at all. Using this method, the Asp202-to-Val mutation was not detected in the father of the two boys or in the $78 \mathrm{X}$ chromosomes of the healthy Japanese individuals. Thus, it is possible that the observed mutation causes the disease.

There have been a few cases of connatal PMD in which the genetic defects were known. Iwaki et al. (1993) first described a mutation (Gly220-to-Cys) in exon 5 of the PLP gene in a Japanese family with a connatal form of PMD. Yamamoto et al. (1998) reported a Japanese male patient in whom PMD was caused by an Ala242-to-Val mutation in the $P L P$ gene. This mutation has been found in the jimpy (msd) mouse, which is a phenotypic model of the human connatal type of PMD (Gow and Lazzarini 1996). The clinical severity in these patients was quite similar to that in the present patients.

Doll et al. (1992) reported another amino acid substitution (Asp $\rightarrow$ His) in codon 202 of PLP, a G-to-C change in the first position of the codon, in a patient with diagnosed

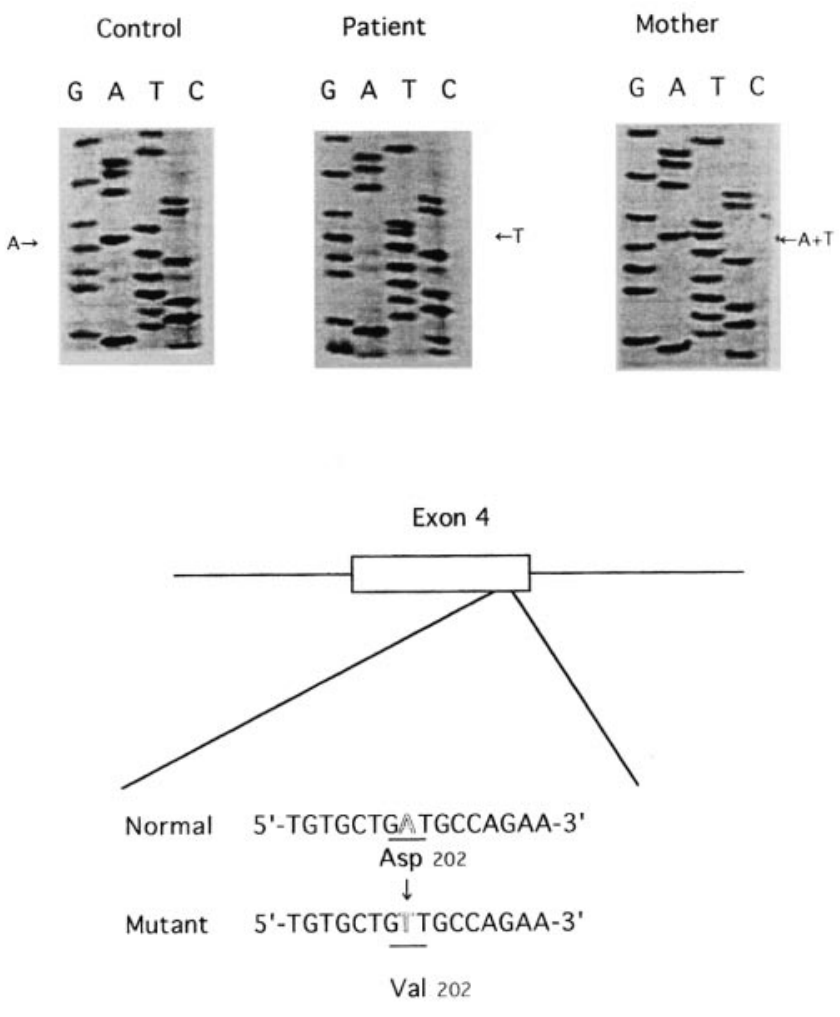

Fig. 1 Identification of the Asp202-to-Val mutation in exon 4 of the $P L P$ gene by the polymerase chain reaction (PCR) cycle sequencing method. The primers used for PCR amplification and sequencing have been described by Doll et al. (1992). The mutant allele bears T instead of $\mathrm{A}$ in the second nucleotide of codon 202. The $\mathrm{A} \rightarrow \mathrm{T}$ transition alters Asp-202 to Val in the PLP gene. This nucleotide substitution was observed in both of the affected male siblings. Mother is a heterozygous carrier
1

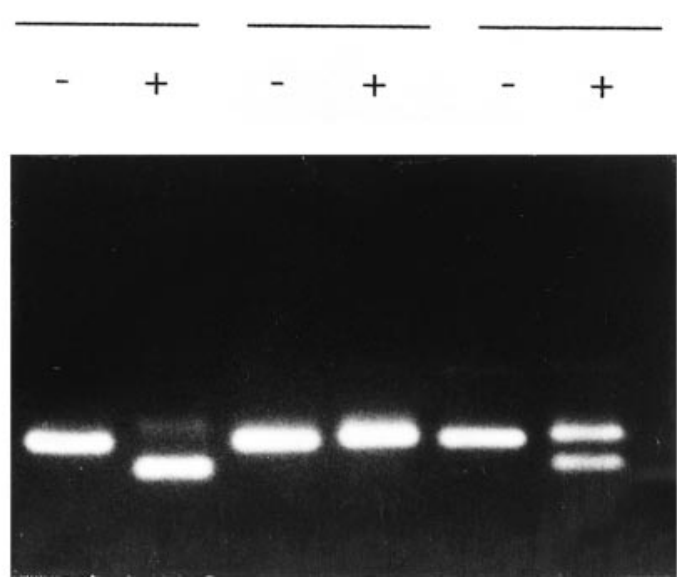

bp 
with the classic form of PMD. The difference in phenotypes between these two missense mutations (Asp202-to-Val and Asp202-to-His) may be explained by a change in charge distribution in the region around residue 202. As suggested by several topology models for PLP (Popot et al. 1991), these two amino acid substitutions could have different effects on the protein structure in a loop between hydrophobic regions $\mathrm{C}$ and $\mathrm{D}$ in the extracellular matrix. Gow and Lazzarini (1996) suggested that connatal PMD mutations led to the accumulation of both mutant PLP and DM20 protein in the endoplasmic reticulum of COS-7 cells. The same mechanism could be involved in the pathogenesis of the Asp202-to-Val mutation at the cellular level.

Abnormalities in the expression of the PLP gene were demonstrated in some patients. Recently, Inoue et al. (1996) reported the presence of a duplicated PLP gene in four of five Japanese families with PMD not carrying exonic mutations. We also estimated the gene dosage of the PLP gene in the family of the present patients, using comparative multiplex PCR (Inoue et al. 1996), but the duplication was not detected (data not shown).

DNA-based tests are necessary not only for identification of the basic defect in the patient but also for the detection of carrier status, and for prenatal diagnosis in the patient's family. PCR amplification followed by sequencing of the seven exons of the PLP gene would be an appropriate choice of approach to detect mutations in patients with the connatal form of PMD.

Acknowledgments This work was supported by a Research Grant (8A-10) for Nervous and Mental Disorders from the Ministry of Health and Welfare of Japan.

\section{References}

Doll R, Natowicz MR, Schiffmann R, Smith FI (1992) Molecular diagnostics for myelin proteolipid protein gene mutations in PelizaeusMerzbacher disease. Am J Hum Genet 51: 161-169

Gencic S, Abuelo D, Ambler M, Hudson LD (1989) PelizaeusMerzbacher disease: An X-linked neurologic disorder of myelin metabolism with a novel mutation in the gene encoding proteolipid protein. Am J Hum Genet 45: 435-442

Gow A, Lazzarini RA (1996) A cellular mechanism governing the severity of Pelizaeus-Merzbacher disease. Nature Genet 13: 422-428

Inoue K, Osaka H, Sugiyama N, Kawanishi C, Onishi H, Nezu A, Kimura K, Kimura S, Yamada Y, Kosaka K (1996) A duplicated PLP gene causing Pelizaeus-Merzbacher disease detected by comparative multiplex PCR. Am J Hum Genet 59: 32-39

Inoue $\mathrm{K}$, Osaka H, Kawanishi C, Sugiyama N, Ishii M, Sugita K, Yamada Y, Kosaka K (1997) Mutations in the proteolipid protein gene in Japanese families with Pelizaeus-Merzbacher disease. Neurology 48: 283-285

Iwaki A, Muramoto T, Iwaki T, Furumi H, Dario-deLeon ML, Tateishi J, Fukumaki Y (1993) A missense mutation in the proteolipid protein gene responsible for Pelizaeus-Merzbacher disease in a Japanese family. Hum Mol Genet 2: 19-22

Koeppen AH, Ronca NA, Greenfield EA, Hans MB (1987) Defective biosynthesis of proteolipid protein in Pelizaeus-Merzbacher disease. Ann Neurol 21: 159-170

Mattei MG, Alliel PM, Dautigny A, Passage E, Pham-Dinh D, Mattei JF, Jolles $\mathrm{P}$ (1986) The gene encoding for the major brain proteolipid (PLP) maps on the $\mathrm{q}-22$ band of the human X chromosome. Hum Genet 72: 352-353

Popot JL, Pham-Dinh D, Dautigny A (1991) Major myelin proteolipid: The 4-alpha-helix topology. J Membr Biol 120: 233-246

Trofatter JA, Pratt VM, Dlouhy SR, Hodes ME (1991) AhaII polymorphism in human X-linked proteolipid protein gene (PLP). Nucleic Acids Res 19: 6057

Yamamoto T, Nanba E, Zhang H, Sasaki M, Komaki H, Takeshita K (1998) Jimpy (msd) mouse mutation and connatal PelizaeusMerzbacher disease. Am J Med Genet 75: 439-440 